\title{
Synthetic Utility of Dizinc Reagents Derived from 1,4-diiodo- and 1,4- dibromooctafluorobutane
}

Peter T. Kaplan, Bo Chen, and David A. Vicic

Department of Chemistry, Lehigh University, 6 E. Packer Ave., Bethlehem, PA 18015. Phone: 1-610-7583466, Fax: 1-610-758-6536.

\section{Table of Contents Graphic}

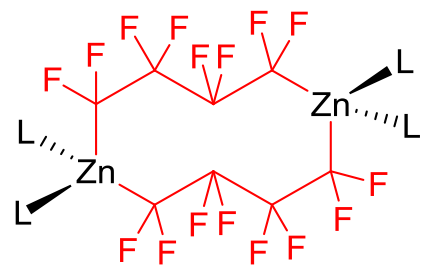

VS.

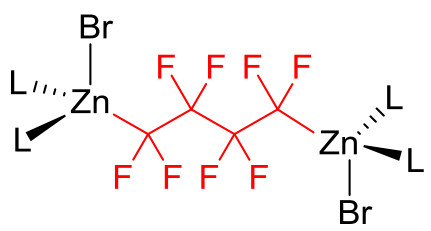

\begin{abstract}
A modified procedure to prepare $\left[(\mathrm{MeCN})_{2} \mathrm{Zn}\left(\left(\mathrm{CF}_{2}\right)_{4}\right)_{2} \mathrm{Zn}(\mathrm{MeCN})_{2}\right]$ has been developed that allows for more reproducible yields of novel organofluorines during cross-coupling protocols. Additionally, the related reagent [(diglyme) $\mathrm{BrZn}-\left(\mathrm{CF}_{2}\right)_{4}-\mathrm{ZnBr}$ (digylme)] has been prepared and was shown to be similarly active for $\left[\mathrm{C}_{4} \mathrm{~F}_{8}\right]$ transfer to both organic and inorganic substrates. The di(zinc halide) reagent is operationally simple to prepare using inexpensive and easy to handle zinc metal.
\end{abstract}

Keywords: Fluoroalkylation; zinc; copper; fluorine

\section{Introduction}

$\alpha, \omega$-difunctionalized perfluoroalkyl nucleophiles have many synthetic applications. With the advances in modern day cross-coupling chemistry, $\left[\mathrm{Nu}-\left(\mathrm{CF}_{2}\right)_{n}-\mathrm{Nu}\right]$ reagents can react with haloarenes or haloheteroarenes to afford perfluoroalkyl-linked dimers (Scheme 1, eq A). ${ }^{1-3}$ Such reagents can also react with 1,2-dihaloarenes and 2,3-dihaloheteroarenes to afford novel ring systems like those described in Scheme 1, eq B. ${ }^{2}$ If the two halogen atoms of the dihaloarenes or dihaloheteroarenes are spaced properly, co-polymeric structures like that shown in Scheme 1, eq C may be also be formed. ${ }^{4} \mathrm{Nu}-$ $\left(\mathrm{CF}_{2}\right)_{n}$-Nu reagents also play a role in organometallic chemistry and reaction development as perfluorometallacycles such as that shown in Scheme 1, eq D can be prepared. ${ }^{2}$ Such metallacycles may 
be used to study insertion chemistry, ring-forming reactions, and high-valent metal chemistry due to the decreased tendency of such metallacycles to undergo beta-fluoride elimination. The $\mathrm{C}_{3}$-derived metallacycle (Scheme 1, eq E) may also be helpful in identifying ligand platforms that could carry out olefin metathesis-like chemistry, which remains a sought-after endeavor.

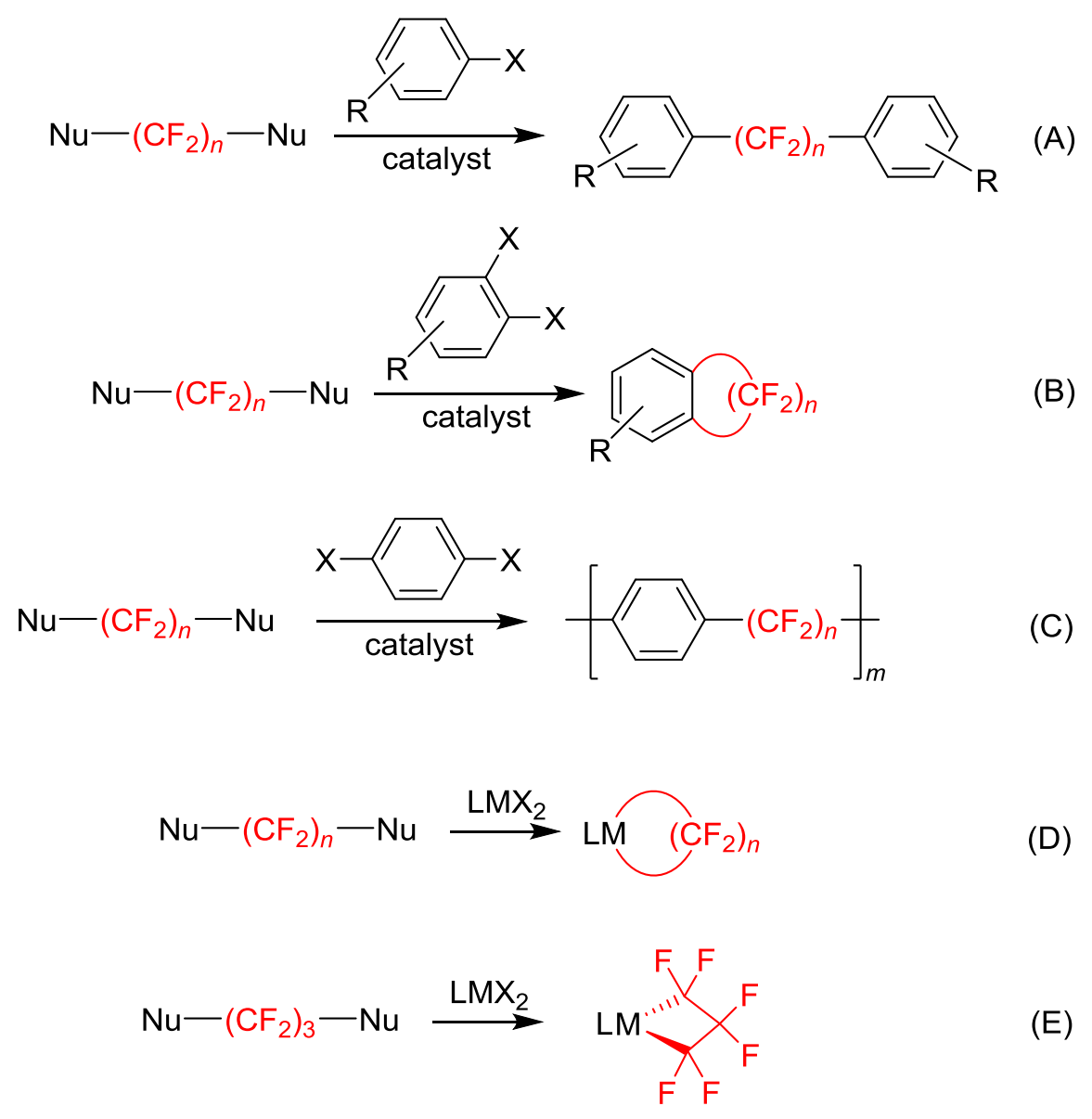

Scheme 1. Applications of $\alpha, \omega$-difunctionalized perfluoroalkyl nucleophiles.

To date, there have been a few methods explored to generate $\alpha, \omega$-difunctionalized perfluoroalkyl nucleophiles. For instance, $\alpha, \omega$-dibrominated perfluoroalkanes can be converted to di-Grignard reagents at low temperatures and then reacted with electrophiles such as $\left[\mathrm{Me}_{3} \mathrm{SiCl}\right]$ to afford bissilylated perfluoroalkanes (Scheme 2, eq A), albeit in low yields. ${ }^{5,6}$ The use of perfluoroalkyl di-Grignard reagents is restrictive because of the low temperatures required for their handling. Denson and coworkers reported that $\left[\mathrm{BrMg}-\left(\mathrm{CF}_{2}\right)_{6}-\mathrm{MgBr}\right]$ has a half-life of only two hours at $-50{ }^{\circ} \mathrm{C} .^{5}$ Efforts have also been made to prepare $\alpha, \omega$-dicuprated perfluoroalkyl reagents directly through the reaction of copper 
metal with $\alpha, \omega$-diiodoperfluoroalkanes. ${ }^{1,4,7}$ Reactions involving the di-copper nucleophiles are often plagued by the requirement of super-stoichiometric amounts of copper metal and/or low to moderate yields of product formation after reaction with substrate, like the example shown in Scheme 2, eq B. ${ }^{1}$ $\left[\mathrm{Me}_{3} \mathrm{Si}-\left(\mathrm{CF}_{2}\right)_{4}-\mathrm{SiMe}_{3}\right]$ has recently been assessed for its ability to generate a $\left[\mathrm{C}_{4} \mathrm{~F}_{8}\right]$ dianion equivalent (Scheme 2, eq C), but it was found that decomposition to $\left[\mathrm{H}-\left(\mathrm{CF}_{2}\right)_{4}-\mathrm{H}\right]$ occurred before any productive reactions with a variety of test substrates. ${ }^{8}$

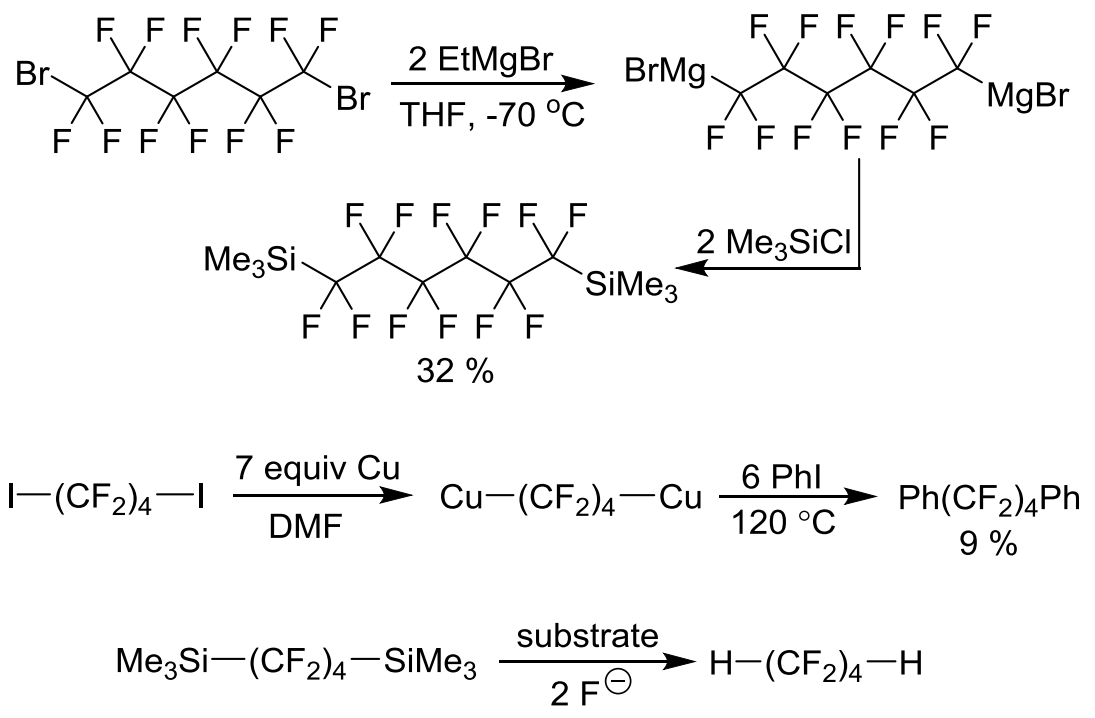

Scheme 2. Selected examples of the generation and use of $\alpha, \omega$-difunctionalized perfluoroalkyl nucleophiles.

Our group recently reported the synthesis of perfluoroalkyl dizinc reagents, prepared by the reaction of $\alpha, \omega$-diiodoperfluoroalkanes with diethyl zinc (eq 1). ${ }^{2,9}$ The zinc reagents 1-3 are unique relative to all other known $\alpha, \omega$-difunctionalized perfluoroalkyl nucleophiles for their stability, easy of handling, and scope of reactivity with organic and organometallic substrates. Of all the zinc complexes prepared, only complex 1 appeared to require special handling conditions as NMR samples of 1 showed large amounts of $\mathrm{H}-\left(\mathrm{CF}_{2}\right)_{4}-\mathrm{H}$ byproduct. Given this anomaly in apparent stability of known $\left(\mathrm{CF}_{2}\right)_{4}$ transfer reagents, we devoted special attention to fine tuning the protocol for the $\mathrm{C}_{4}$ dizinc reagent 1 . It was discovered in the course of these studies (see below) that complex 1 is indeed a stable and storable reagent, and formation of $\mathrm{H}-\left(\mathrm{CF}_{2}\right)_{4}-\mathrm{H}$ byproduct is merely related to the initial stoichiometry of diethyl zinc used in its preparation. Moreover, we further expand the utility of the dizinc chemistry by reporting a new and 
related $\mathrm{C}_{4}$ reagent that does not require the use of air-sensitive diethyl zinc as the metalating reagent (see below).

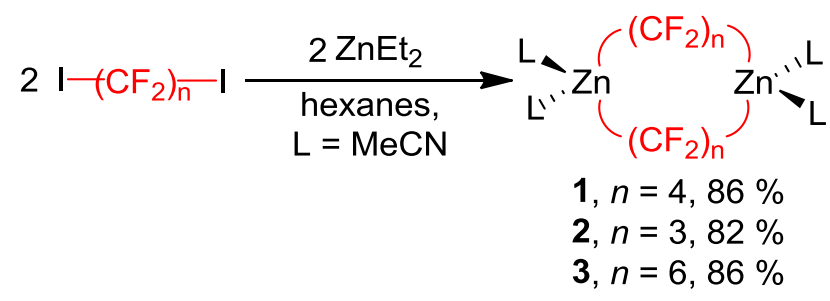

\section{Results and Discussion}

Our initial synthesis of 1 involved reacting 1 mole of diethyl zinc to one mole 1,4-

diiodooctafluorobutane, or a 1:2 ratio of zinc to iodine atoms (zinc reagent " $1 a^{\prime \prime}$ ). ${ }^{2}$ We found that a much cleaner and more crystalline material can be obtained if a 1:1 ratio of zinc to iodine was used (zinc reagent " $\mathbf{1} \mathbf{b}$ ", see Experimental section). Moreover, the product that is obtained with the new procedure shows no initial contamination with $\mathrm{H}-\left(\mathrm{CF}_{2}\right)_{4}-\mathrm{H}$ and gives higher and more consistent yields of cross-coupled product for the reactions described in Table 1. For instance, the conversion of 2,3diiodopyridine to octafluorotetrahydroquinoline increased from 90 to $99 \%$ when using $\mathbf{1 b}$ prepared by the updated protocol (Table 1, entry 1). More impressively however, reactions with unactivated aryl diiodides proceeded smoothly, and the yield of octafluorotetrahydronaphthalene rose from 28 to $80 \%$ when using $\mathbf{1 b}$ (Table 1 , entry 2 ). We speculate that the higher yields with $\mathbf{1} \mathbf{b}$ are due to less contamination of the perfluoroalkylzinc reagent with $\mathrm{L}_{n} \mathrm{Zn}\left(\mathrm{CF}_{2}\right)_{4} \mathrm{H}$ or $\mathrm{ZnI}_{2}$ byproducts. 
Table 1. Dependence of the yields of cross-coupling products on the method used to prepare 1.

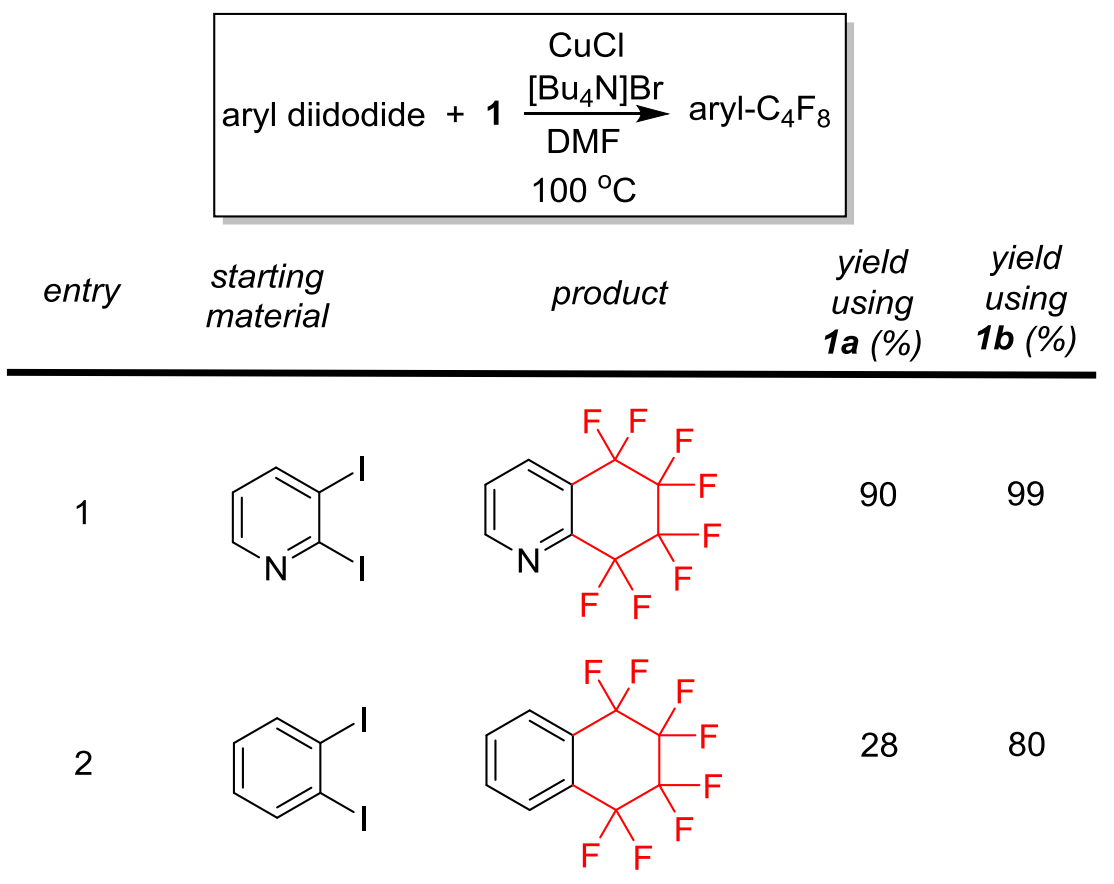

${ }^{a}$ 1a: Complex 1 prepared using one mole diethyl zinc to one mole 1,4-diiodooctafluorobutane. ${ }^{2} \mathbf{1 b}$ : Complex $\mathbf{1}$ prepared using two moles diethyl zinc to one mole 1,4-diiodooctafluorobutane (see Experimental Section).

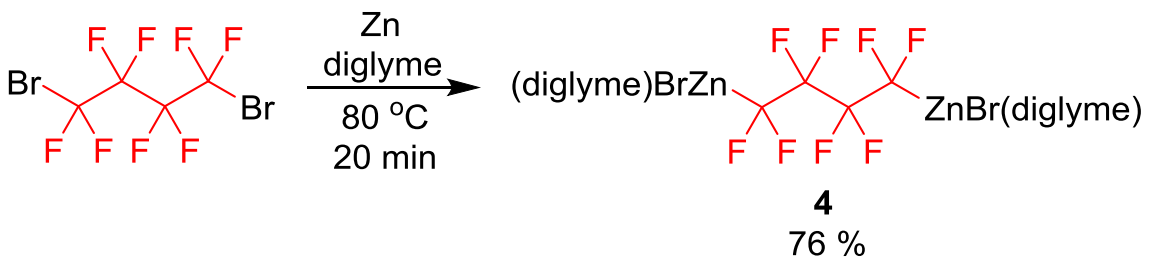

We have also developed a more user friendly procedure to prepare a related perfluoroalkyl dizinc reagent as described in eq 2 . We found that $\mathrm{Br}-\left(\mathrm{CF}_{2}\right)_{4}-\mathrm{Br}$ reacts with zinc metal in diglyme solvent to afford the new reagent 4 in $76 \%$ yield. When prepared in this manner, 4 precipitates from solution and can simply be filtered and used without further purification. Diglyme was key to the synthesis as other solvents did not lead to the precipitation of a dizinc species and afforded complex mixtures by ${ }^{19} \mathrm{~F} \mathrm{NMR}$ spectroscopy. Although insoluble in diglyme, the [(diglyme) $\mathrm{BrZn}-\left(\mathrm{CF}_{2}\right)_{4}-\mathrm{ZnBr}$ (digylme)] reagent 4 can be recrystallized from most organic solvents to afford other ligated zinc complexes. For instance, recrystallization from THF/pentane affords the bis-THF adduct [(THF $\left.)_{2} \mathrm{BrZn}-\left(\mathrm{CF}_{2}\right)_{4}-\mathrm{ZnBr}(\mathrm{THF})_{2}\right](5)$. X-ray diffraction analysis confirms the structure of $\mathbf{5}$ (Figure 1). 


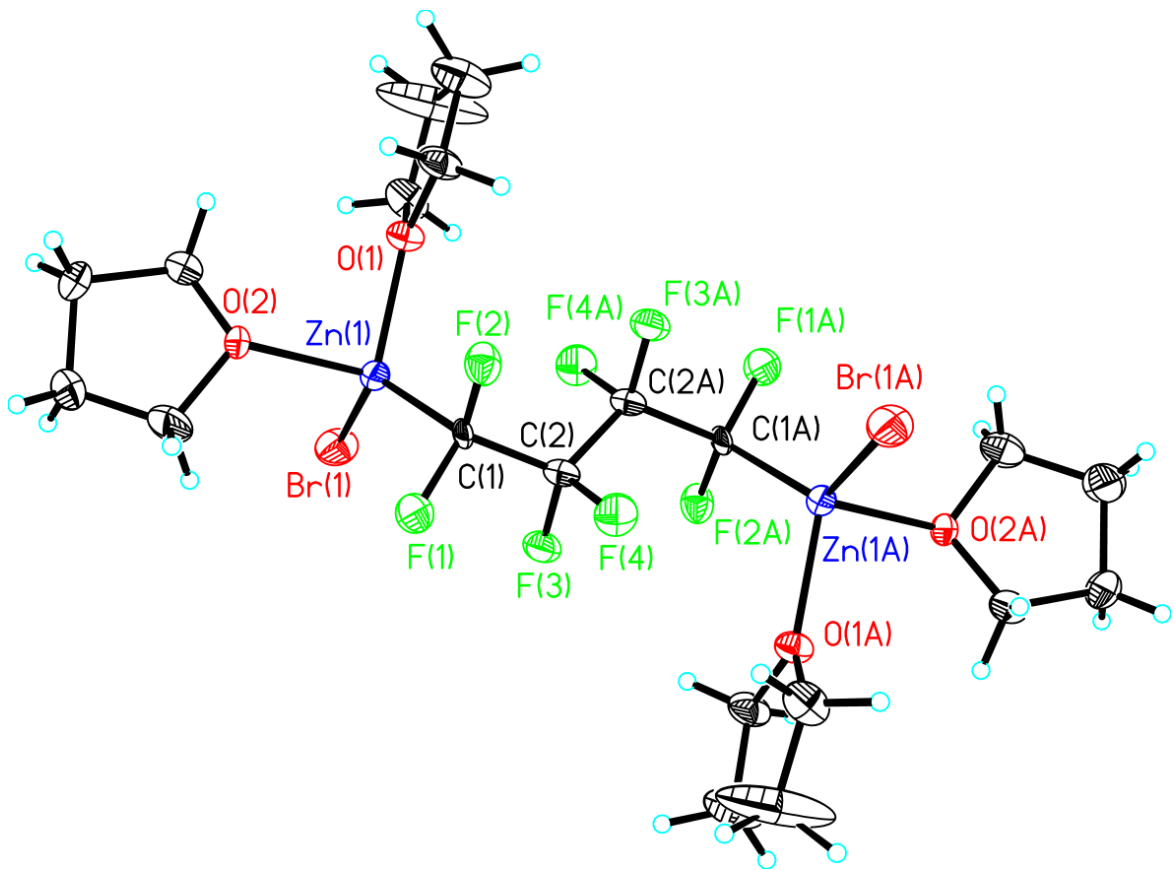

Figure 1. ORTEP diagram of 5. Selected bond lengths (Å): Zn1-O1 2.034(10); Zn1-C1 2.058(16); Zn1-O2 2.073(10); Zn1-Br1 2.338(2); C1-C2 1.517(19). Selected bond angles ( $\left.{ }^{\circ}\right)$ : O1-Zn1-C1 112.3(5); O1-Zn1-O2 93.1(4); C1-Zn1-O2 107.9(5); O1-Zn1-Br1 108.5(3); C1-Zn1-Br1 126.6(4); O2-Zn1-Br1 102.6(3); C2-C1-Zn1 116.1(11).

The isolated zinc species 4, when dissolved in acetonitrile, shows excellent thermal stability. Figure 2 shows a plot of concentration over time of both $\mathbf{1 b}$ and $\mathbf{4}$ in acetonitrile solution. Unlike $\alpha, \omega$ difunctionalized perfluoroalkyl di-Grignard reagents, which have a half-life of only two hours at $-50{ }^{\circ} \mathrm{C}$ in $\mathrm{THF}^{5}$ we observed that $87 \%$ of the dizinc reagents persist in acetonitrile solution after $300 \mathrm{~h}$ at room temperature. Besides exceptional solution stability, the advantages of our new protocol involving zinc metal are manifold. First, zinc metal is far less expensive than diethyl zinc and does not require storage under air-free conditions. Secondly, $\mathrm{Br}-\left(\mathrm{CF}_{2}\right)_{4}$ - $\mathrm{Br}$ is over three times less expensive per mole, based on current retail prices from Synquest Labs. Third, no evidence of dicuprate formation (6, Scheme 3$)$ is observed in mixtures of complex $\mathbf{4}$ and $\mathrm{CuCl}$ in DMF. We have previously reported that zinc dimer 1 readily reacts with $\mathrm{CuCl}$ to afford 6 , which is inactive towards coupling with aryl iodides. [Bu $4 \mathrm{~N}][\mathrm{Br}]$ needed to be added to reaction mixtures containing 1 before the addition of $\mathrm{CuCl}$ to prevent the formation of $\mathbf{6}$ and afford good yields of cross-coupling products. ${ }^{2}$ The reactivity of 4 permits the crosscoupling reactions to be performed in the absence of any added $\left[\mathrm{Bu}_{4} \mathrm{~N}\right][\mathrm{Br}]$ (see below). 


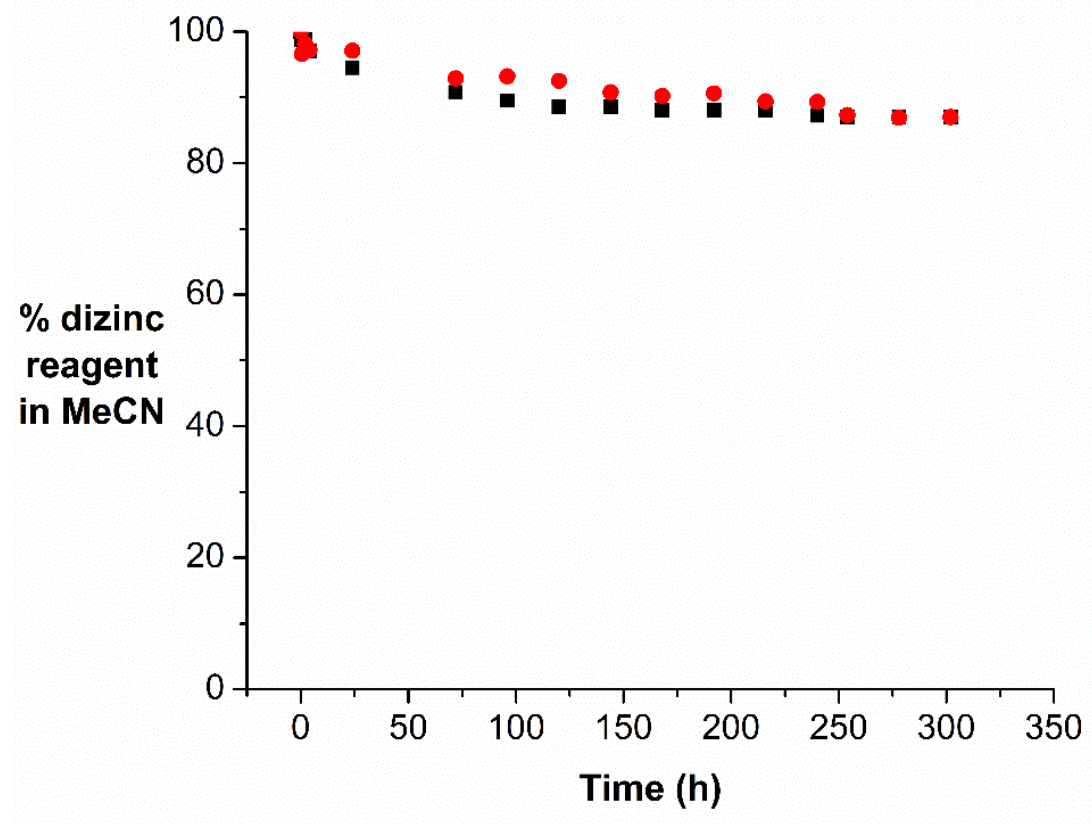

Figure 2. Plot of concentration vs time for $\mathbf{1 b}$ (red circles, $0.05 \mathrm{mmol}$ ) and $\mathbf{4}$ (black squares, $0.1 \mathrm{mmol}$ ) in $0.5 \mathrm{~mL}$ acetonitrile. Concentrations were monitored by ${ }^{19} \mathrm{~F} \mathrm{NMR}$ spectroscopy versus trifluorotoluene as an internal standard.

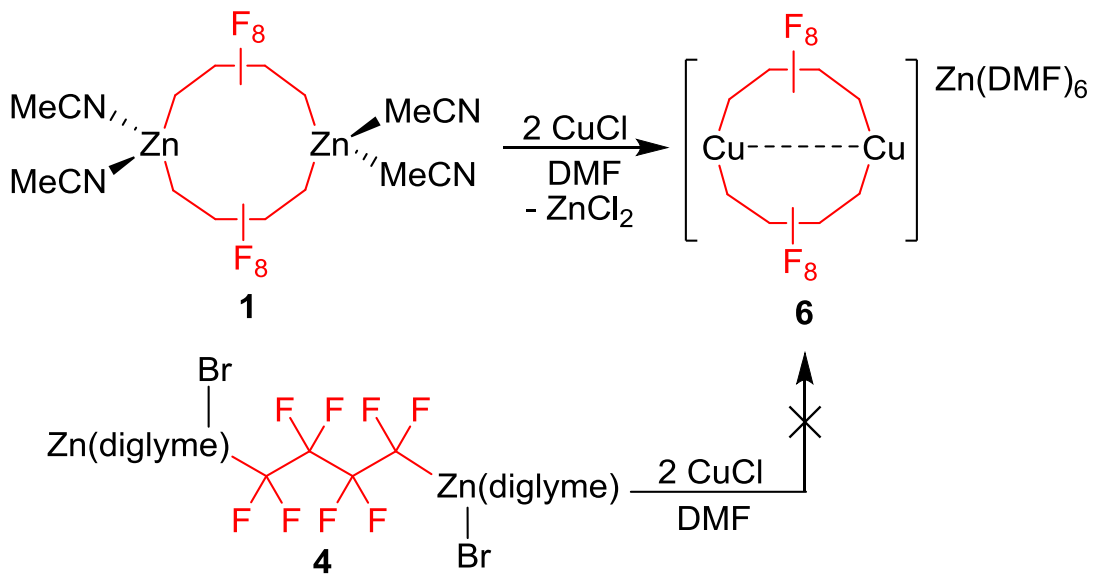

Scheme 3. Reactivity of $\mathbf{1}$ and $\mathbf{4}$ towards $\mathrm{CuCl}$ in DMF solution.

The dizinc reagents $\mathbf{1 b}$ and $\mathbf{4}$ were evaluated for their ability to transfer the $\left[\mathrm{C}_{4} \mathrm{~F}_{8}\right]$ moiety to diiodoarenes, and the results are provided in Table 2. For the 2,3-diiodopyridine and 1,2-diiodobenzene 
model substrates, complex $\mathbf{1 b}$ outperformed $\mathbf{4}$ (Table 2, entries 1 and 2). DMPU has been reported to dramatically increase the yields of cross-coupling reactions involving perfluoroalkylzinc reagents, ${ }^{3,10}$ so runs using DMF/DMPU solvent mixtures were also run to evaluate solvent effects. Surprisingly, with the exception of the 1,2-diiodobenzene substrate (Table 2, entry 2), DMPU had a deleterious effect on reaction yields with zinc reagent 4. 1,8-diiodonaphthalene was found to be exceptionally prone to fluoroalkylation, and $\mathbf{9}$ was produced in near quantitative yields using reagent $\mathbf{1}$ (Table 2, entry 3 ). Compound 9 was structurally characterized, and an ORTEP diagram of 9 is shown in Figure 3. 2,3Diiodonaphthalene, 1,2-diiodo-4,5-dimethoxybenzene, and 1,2-difluoro-4,5-diiodobenzene all reacted with the dizinc reagents $\mathbf{1 b}$ and $\mathbf{4}$ to give fluoroalkylation products in good to moderate yields (Table 2 , entries 4-6). In general, the dizinc reagent $\mathbf{1 b}$ slightly outperformed $\mathbf{4}$ for fluoroalkylating dihaloarenes. However, the operationally simple protocol to prepare $\mathbf{4}$ may ultimately render it a more attractive reagent for those ill-equipped to handle diethyl zinc. 
Table 2. Evaluation of the dizinc reagents in cross-coupling reactions.

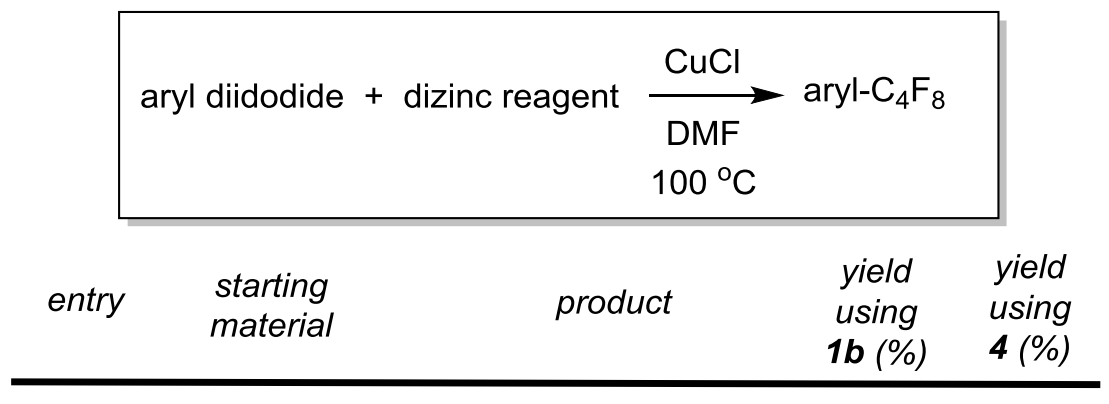

1<smiles>Ic1cccnc1I</smiles>

2<smiles>Ic1ccccc1I</smiles>

3<smiles>Ic1cccc2cccc(I)c12</smiles>

4<smiles>Ic1cc2ccccc2cc1I</smiles>

99

$84,86^{\mathrm{a}}$

80

$44,99^{\mathrm{a}}$<smiles>FC1(F)c2ccccc2C(F)(F)C(F)(F)C1(F)F</smiles><smiles>FC1(F)c2cccc3cccc(c23)C(F)(F)C1(F)F</smiles>

99 $81,61^{a}$

9<smiles>FC1(F)c2cc3ccccc3cc2C(F)(F)C(F)(F)C1(F)F</smiles>

90

$65,63^{a}$

5<smiles>COc1cc(I)c(I)cc1OC</smiles>

6<smiles>COc1cc2c(cc1OC)C(F)(F)C(F)(F)C(F)(F)C2(F)F</smiles>

88

$50,28^{a}$

${ }^{\mathrm{a} A}$ 1:1 mixture of DMF/DMPU was used as solvent. 


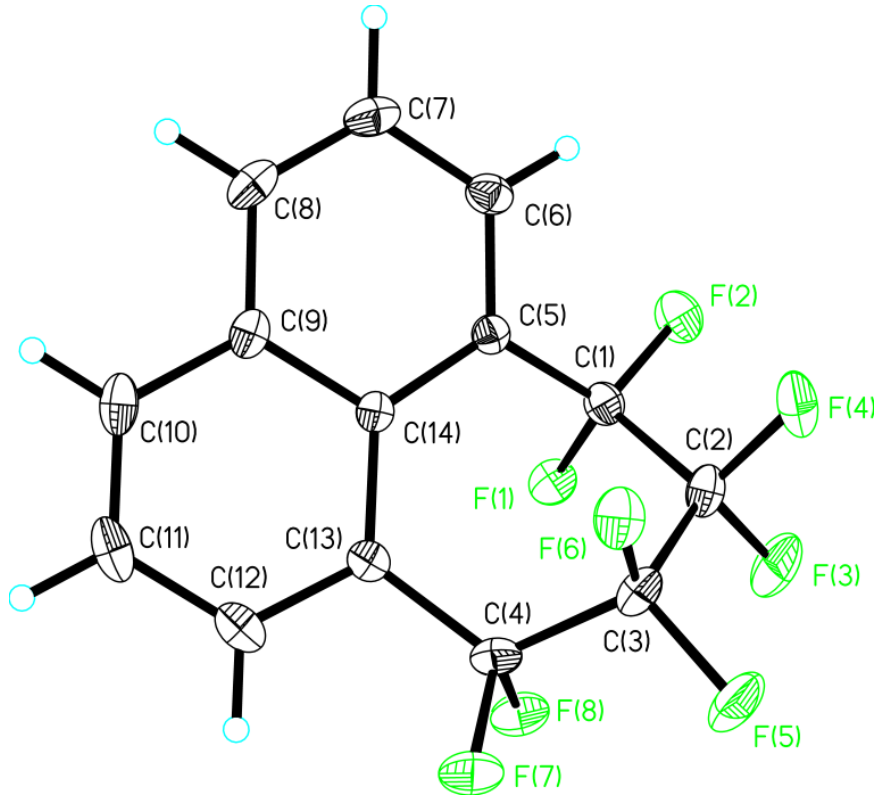

Figure 3: ORTEP diagram of 9. Selected bond lengths (Å): C1-C5 1.5007(15); C1-C2 1.5376(17); C2-C3 1.5426(17); C3-C4 1.5426(17); C4-C13 1.5118(16). Selected bond angles ( ${ }^{\circ}$ ): C5-C1-C2 116.29(9); C1-C2C3 115.21(9); C2-C3-C4 116.63(10); C13-C4-C3 116.91(9); C14-C13-C4 124.53(10).

Complex 4 is also capable of transmetalating $\left[(\mathrm{dme}) \mathrm{NiBr}_{2}\right]$ to afford the known [(MeCN $\left.)_{2} \mathrm{Ni}\left(\mathrm{C}_{4} \mathrm{~F}_{8}\right)\right](\mathbf{1 3}$, eq 3), although $\mathbf{1 b}$ displays cleaner transmetalation reactivity. The acetonitrile ligands in $\mathbf{1 3}$ are labile, which makes 13 a useful synthetic precursor to a variety of $\left[\mathrm{LNi}\left(\mathrm{C}_{4} \mathrm{~F}_{8}\right]\right.$ complexes. ${ }^{2}$ Previous to the discovery of the dizinc reagents described herein and elsewhere, ${ }^{2}$ the only previously known method for preparing metallacycles bearing the $\left[\mathrm{C}_{4} \mathrm{~F}_{8}\right]$ fragment was through the oxidative coupling of tetrafluoroethylene by low valent metal complexes. ${ }^{2}$ Such routes are problematic for discovery research because of the explosion hazards associated with handling tetrafluoroethylene. ${ }^{2}$

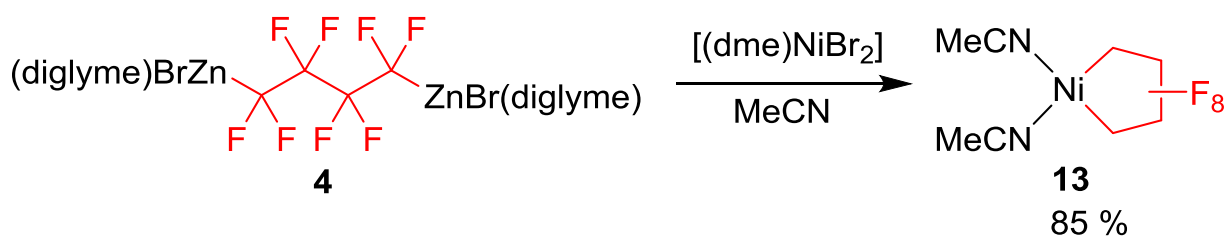

\section{Conclusions}

A modified procedure to prepare $\left[(\mathrm{MeCN})_{2} \mathrm{Zn}\left(\left(\mathrm{CF}_{2}\right)_{4}\right)_{2} \mathrm{Zn}(\mathrm{MeCN})_{2}\right](\mathbf{1})$ has been developed that allows for more reproducible yields of novel organofluorines during cross-coupling protocols. Additionally, the related reagent [(diglyme) $\mathrm{BrZn}-\left(\mathrm{CF}_{2}\right)_{4}-\mathrm{ZnBr}$ (digylme)] (4) has been prepared and was shown to be 
similarly active for $\left[\mathrm{C}_{4} \mathrm{~F}_{8}\right]$ transfer to both organic and inorganic substrates. The dizinc reagent 4 is operationally simple to prepare using inexpensive and easy to handle zinc metal.

\subsection{Experimental Procedures}

4.1 General Considerations: All manipulations were performed using standard Schlenk and high vacuum techniques or in a nitrogen filled glovebox. ${ }^{11}$ Solvents were purified by passing through activated alumina and/or copper in a solvent purification system supplied by Pure Process Technology. 1,4-diiodo- and 1,4-dibromooctafluorobutane were purchased from SynQuest Labs, Inc. and used without further purification. The diiodoarenes were either purchased commercially from Aldrich and used without further purification or synthesized according to known procedures. ${ }^{12}$ Solution ${ }^{1} \mathrm{H}$ NMR spectra were recorded at ambient temperature on a Bruker DRX $500 \mathrm{MHz}$ spectrometer and referenced to residual proton solvent signals. ${ }^{13} \mathrm{C}$ NMR spectra were recorded on a Bruker NMR spectrometer operating at $125 \mathrm{MHz}$ and referenced to solvent signals. ${ }^{19} \mathrm{~F}$ spectra were recorded on the Bruker NMR spectrometer operating at $470 \mathrm{MHz}$ and referenced to $\alpha, \alpha, \alpha$-trifluorotoluene at $\delta$-67.3. A Bruker D8 Quest diffractometer was used for X-ray crystal structure determinations. Elemental Analyses were performed at Midwest Microlab, LLC. Analytical data for compounds $\mathbf{7}$ and $\mathbf{8}$ have previously been reported. ${ }^{2}$ Mass spectral data (TOF MS EI ${ }^{+}$) was provided by the Notre Dame Mass Spectrometry and Proteomics Facility. Crystallographic data (excluding structure factors) for compounds $\mathbf{4}$ and $\mathbf{9}$ have been deposited with the Cambridge Crystallographic Data Centre as supplementary publication number CCDC 1021501 and 1021502, respectively. Copies of the data can be obtained free of charge on application to CCDC, 12 Union Road, Cambridge CB2 1EZ, UK [fax: +44 1223336 033; e-mail: deposit@ccdc.cam.ac.uk].

4.1.1. Synthesis of dizinc complex $1 \mathrm{~b}$ : An $8 \mathrm{~mL}$ portion of a $1.0 \mathrm{M}$ diethyl zinc solution in hexanes was prechilled in a vial to $-78^{\circ} \mathrm{C}$ under a nitrogen atmosphere. 1,4-Diiodooctafluorobutane $(1.82 \mathrm{~g}, 4 \mathrm{mmol})$ was diluted with $8 \mathrm{~mL}$ of pentane and was also prechilled to $-78^{\circ} \mathrm{C}$. The zinc solution was then added dropwise to the 1,4-diiodooctafluorobutane solution at $-78^{\circ} \mathrm{C}$. The reaction vial was then stirred for $3 \mathrm{~h}$ at $-20^{\circ} \mathrm{C}$. After $3 \mathrm{~h}, 4 \mathrm{~mL}$ of $\mathrm{MeCN}$ was then added and the mixture was stirred vigorously for 15 mins and then warmed to room temperature. The pentane layer was decanted away, and benzene was added to precipitate an off-white solid. The mixture sat overnight, and then the solid was pumped dry on a 
high-vacuum line. The product was obtained in $86 \%$ yield as a white solid. Analytical data matched previously reported literature values. ${ }^{2}$

4.1.2. Preparation of dizinc complex 4: To a resealable pressure tube was added Zn dust $(0.3925 \mathrm{~g}, 6$ $\mathrm{mmol}$ ) and a solution of $\mathrm{Br}\left(\mathrm{CF}_{2}\right)_{4} \mathrm{Br}(1.2604 \mathrm{~g}, 3.5 \mathrm{mmol})$ in diglyme $(4 \mathrm{~mL})$ under $\mathrm{N}_{2}$ atmosphere at room temperature. The resulting mixture was sealed and quickly submerged in an oil bath preheated to $80^{\circ} \mathrm{C}$. After $20 \mathrm{~min}$, the mixture was cooled to room temperature and filtered. The product was rinsed with diglyme followed by pentane to afford dizincbromide diglyme complex 4 (1.7237 g, 76\%): white/grey solid. ${ }^{19} \mathrm{~F}$ NMR (471 MHz, THF- $\left.d_{8}\right) \delta-122.52(\mathrm{~s}, 4 \mathrm{~F}),-124.27$ (s, 4F). Anal. Calcd (found) for $\mathrm{C}_{16} \mathrm{H}_{28} \mathrm{Br}_{2} \mathrm{~F}_{8} \mathrm{O}_{6} \mathrm{Zn}_{2}$ : C, 25.32 (23.50); H, 3.72 (3.60). Recrystallization from THF/Pentane affords X-ray quality crystals of 5 .

4.1.3. General procedure for the preparation of organofluorines in Table $\mathbf{2}$ using reagent $\mathbf{1 b}$ : The dizinc reagent $1 \mathrm{~b}$ (69.5 mg, $0.1 \mathrm{mmol}$ ) was dissolved in $1.0 \mathrm{~mL}$ of DMF in a $20 \mathrm{~mL}$ reaction vial. Tetra- $N$ butylammonium bromide (TBAB) was added $(64.5 \mathrm{mg}, 0.2 \mathrm{mmol})$ to the solution and the resulting mixture was stirred. Then $0.1 \mathrm{mmol}$ of the diiodoarene and $\mathrm{CuCl}(9.9 \mathrm{mg}, 0.1 \mathrm{mmol})$ were added to the stirred solution. $0.012 \mathrm{~mL}$ of $\alpha, \alpha, \alpha$-trifluorotoluene $(0.098 \mathrm{mmol})$ syringed into the solution as the internal standard. The solution was transferred to a J. Young NMR tube fitted with a Teflon screw cap and was heated for 3 hours at $100{ }^{\circ} \mathrm{C}$. After analysis of NMR yields, the solution in the NMR tube was diluted with hexanes and washed with water. The hexane layer was dried over anhydrous $\mathrm{Na}_{2} \mathrm{SO}_{4}$, and all volatiles were removed under vacuum.

\subsubsection{General procedure for the preparation of organofluorines in Table 2 using reagent 4: To a} resealable pressure tube was added the zinc complex (379.7 mg, $0.5 \mathrm{mmol})$, copper chloride (19.9 mg, $0.2 \mathrm{mmol}$ ), and $0.1 \mathrm{mmol}$ of diiodoarene in $1 \mathrm{~mL}$ of DMF under $\mathrm{N}_{2}$ atmosphere at room temperature. The resulting mixture was sealed and quickly submerged in an oil bath preheated to $100{ }^{\circ} \mathrm{C}$. After $3 \mathrm{~h}$, the mixture was cooled to room temperature and $0.012 \mathrm{~mL}$ of $\alpha, \alpha, \alpha$-trifluorotoluene $(0.098 \mathrm{mmol}$ ) was syringed into the tube as the reference standard. After analysis of NMR yields, the solution was diluted with hexanes and washed with water. The hexane layer was dried over anhydrous $\mathrm{Na}_{2} \mathrm{SO}_{4}$, and all volatiles were removed under vacuum.

\subsubsection{General procedure for the preparation of organofluorines in Table 2 using reagent 4 and} DMF/DMPU solvent: To a resealable NMR tube was added the zinc complex (190.0 mg, $0.25 \mathrm{mmol}$ ), copper chloride ( $9.9 \mathrm{mg}, 0.1 \mathrm{mmol}$ ), diiodoarene $(0.05 \mathrm{mmol}), 0.5 \mathrm{~mL}$ of DMF and $0.5 \mathrm{~mL}$ of DMPU under 
$\mathrm{N}_{2}$ atmosphere at room temperature. Lastly, $0.012 \mathrm{~mL}$ of $\alpha, \alpha, \alpha$-trifluorotoluene $(0.098 \mathrm{mmol})$ was syringed into the tube as the internal standard. The resulting mixture was sealed and quickly submerged in an oil bath and heated at $100{ }^{\circ} \mathrm{C}$ for $3 \mathrm{~h}$. After analysis of NMR yields, the product was collected from a hexane/water separation where the hexane layer was taken and dried over anhydrous $\mathrm{Na}_{2} \mathrm{SO}_{4}$. The residue was concentrated under vacuum.

4.1.6. Analytical data for 7,7,8,8,9,9,10,10-octafluoro-7,8,9,10-tetrahydrocyclohepta[de] naphthalene (9): ${ }^{19} \mathrm{~F} \mathrm{NMR}\left(\mathrm{CDCl}_{3}, 470 \mathrm{MHz}\right): \delta-103.88(\mathrm{~s}, 4 \mathrm{~F}),-128.16(\mathrm{~s}, 4 \mathrm{~F}) .{ }^{1} \mathrm{H}$ NMR $\left(\mathrm{CDCl}_{3}, 300 \mathrm{MHz}\right): \delta 8.17\left(\mathrm{~d}, \mathrm{~J}_{\mathrm{HH}}\right.$ $=7.4 \mathrm{~Hz}, 2 \mathrm{H}), 8.12\left(\mathrm{~d}, J_{\mathrm{HH}}=8.2 \mathrm{~Hz}, 2 \mathrm{H}\right), 7.69\left(\mathrm{t}, \mathrm{J}_{\mathrm{HH}}=7.8 \mathrm{~Hz}, 2 \mathrm{H}\right)$. Exact mass $\left(\mathrm{EI}^{+}\right)$calcd for $\mathrm{C}_{14} \mathrm{H}_{6} \mathrm{~F}_{8}$ 326.0345 , found 326.0342 .

4.1.7. Analytical data for $1,1,2,2,3,3,4,4$-octafluoro-1,2,3,4-tetrahydoanthracene (10): ${ }^{19} \mathrm{~F} \mathrm{NMR}\left(\mathrm{CDCl}_{3}\right.$, $470 \mathrm{MHz}$ ): $\delta$-102.02 (s, 4F), -135.09 (s, 4F). NMR (CDCl, $300 \mathrm{MHz}): \delta 8.43(\mathrm{~s}, 2 \mathrm{H}), 8.05$ (dd, $J_{H H}=6.2,3.3$ $\mathrm{Hz}, 2 \mathrm{H}), 7.76\left(\mathrm{dd}, \mathrm{J}_{\mathrm{HH}}=6.3,3.2 \mathrm{~Hz}, 2 \mathrm{H}\right)$. Exact mass $\left(\mathrm{EI}^{+}\right)$calcd for $\mathrm{C}_{14} \mathrm{H}_{6} \mathrm{~F}_{8} 326.0345$, found 326.0342 .

\subsubsection{Analytical data for 1,1,2,2,3,3,4,4-octafluoro-6,7-dimethoxy-1,2,3,4-tetrahydronaphthalene} (11): ${ }^{19} \mathrm{~F} \mathrm{NMR}\left(\mathrm{CDCl}_{3}, 470 \mathrm{MHz}\right): \delta-102.61(\mathrm{~s}, 4 \mathrm{~F}),-134.97(\mathrm{~s}, 2 \mathrm{~F}) .{ }^{1} \mathrm{H} N \mathrm{NMR}\left(\mathrm{CDCl}_{3}, 300 \mathrm{MHz}\right): \delta 7.19$ (s, 2 $\mathrm{H}), 4.01(\mathrm{~s}, 6 \mathrm{H})$. Exact mass $\left(\mathrm{El}^{+}\right)$calcd for $\mathrm{C}_{12} \mathrm{H}_{8} \mathrm{~F}_{8} \mathrm{O}_{2}: 336.0374$, found 336.0397 .

4.1.9. Analytical data for $1,1,2,2,3,3,4,4,6,7$-decafluoro-1,2,3,4-tetrahydronaphthalene (12): ${ }^{19} \mathrm{~F} N M R$ (DMF, $470 \mathrm{MHz}$ ): $\delta 103.17$ (s, 4F), -135.11 (s, 2F), -136.70 (s, 4F). ${ }^{1} \mathrm{H}$ NMR (CDCl, $\left.300 \mathrm{MHz}\right): \delta 7.72$ $\left(\mathrm{dd}, J_{\mathrm{HH}}=8.2 \mathrm{~Hz}, 2.0 \mathrm{H}\right.$ ). Exact mass $\left(\mathrm{EI}^{+}\right)$calcd for $\mathrm{C}_{10} \mathrm{H}_{2} \mathrm{~F}_{10} 312.0122$, found 311.9997.

4.1.10. Preparation of $\left[(\mathrm{MeCN})_{2} \mathrm{Ni}\left(\mathrm{C}_{4} \mathrm{~F}_{8}\right)\right]$ (13) from dizinc complex 4: [(dme) $\left.\mathrm{NiBr}_{2}\right]$ (30.9 mg, $\left.0.1 \mathrm{mmol}\right)$, and complex 4 (151.8 mg, $0.2 \mathrm{mmol}$ ) was dissolved in $2 \mathrm{~mL}$ of MeCN and stirred for 3 hours at room temperature in a glovebox, and then the volatiles were removed under vacuum. The nickel complex was extracted from the residue with benzene, and this benzene solution was filtered then dried under vacuum to yield a yellow solid ( $289.7 \mathrm{mg}, 85 \%)$. Analytical data matched previously reported literature values. $^{2}$

Acknowledgements: D.A.V. thanks the Office of Basic Energy Sciences of the U.S. Department of Energy (DE-FG02-13ER16369) for support of this work. 


\section{References}

(1) V.C.R. McLoughlin, J. Thrower, Tetrahedron, 25 (1969) 5921.

(2) P. T. Kaplan, L. Xu, B. Chen, K. R. McGarry, S. Yu, H. Wang, D. A. Vicic, Organometallics 32 (2013) 7552.

(3) I. Popov, S. Lindeman, O. Daugulis, J. Am. Chem. Soc., 133 (2011)9286.

(4) S. -J. Yoon, J. -H. Choi, Y. T. Hong, S. -Y. Lee, Macromol. Res., 18 (2010) 352.

(5) D. D. Denson, G. J. Moore, C. Tamborski, J. Fluorine Chem., 5 (1975) 475.

(6) A. E. Jukes, H. Gilman, J. Organomet. Chem., 18 (1969) P33.

(7) M. H. Hung, Tetrahedron Lett., 31 (1990) 3703.

(8) B. Chen, D. A. Vicic, J. Fluorine Chem. 2014, DOI: 10.1016/j.jfluchem.2014.06.023.

(9) The composition of matter and methods to prepare 1, 4, and derivatives thereof are covered by US patent application PCT/US2014/45673.

(10) Y. Nakamura, M. Fujiu, T. Murase, Y. Itoh, H. Serizawa, K. Aikawa, K. Mikami, Beilstein J. Org. Chem., 9 (2013) 2404.

(11) D. A. Vicic, G. D. Jones, Comprehensive Organometallic Chemistry III; Crabtree, R. H., Mingos, D. M. P., Eds.; Elsevier: 2006; Vol. 1.

(12) D. Rodríguez-Lojo, A. Cobas, D. Peña, D. Pérez, E. Guitián, Organic Letters, 14 (2012) 1363-1365. 

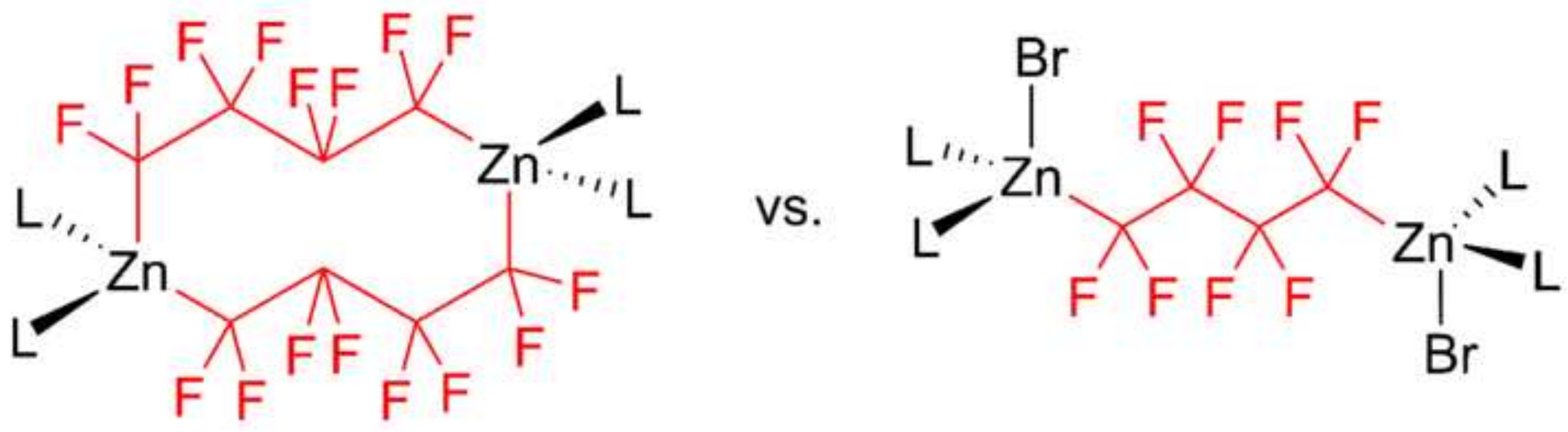